\title{
Siroz etiyolojisinde steatohepatitin yeri nedir?
}

\author{
The role of steatohepatitis in cirrhosis etiology
}

\author{
(D)Ahmet UYANIKOĞLU
}

Harran Üniversitesi, Tıp Fakültesi, Gastroenteroloji Bilim Dalı, Şanlıurfa

\begin{abstract}
Giriş ve Amaç: Karaciğer sirozunun etiyolojisinde Türkiye'de ve bölgemizde en önemli sebep kronik viral hepatitlerdir. Etiyolojik bir neden bulunamazsa kriptojenik siroz olarak tanımlanır. Non-alkolik steatohepatit yağlanmaya sebep ikincil bir nedenin olmadı̆̆ı, kronik inflamasyonla seyreden ve siroza kadar ilerleyebilen bir hastalıktır. Bu çalışmada bölgemizde siroz etiyolojisi ve siroz etiyolojisinde non-alkolik steatohepatitin yerini değerlendirmeyi amaçladık. Gereç ve Yöntem: Çalışmaya Ocak 2013-Aralık 2014 arasında klinik ve/veya biyopsi ile siroz teşhisi konulmuş hastalar alındı. Hastaların ayrıntıı anamnezi alındı, fizik muayeneleri yapıldı, vücut kitle indeksleri hesaplandı. Rutin tetkikleri, etiyolojik açıdan ayrıntılı laboratuvar ve radyolojik incelemeleri yapıldı. Etiyolojik bir neden bulunamayan hastalar kriptojenik siroz kabul edildi, bu hastalar Adult Treatment Panel 3 kriterlerine göre metabolik sendrom açısından değerlendirildi, bu kriterlere uyan hastalar non-alkolik steatohepatit zemininde gelişen siroz kabul edildi. Bulgular: Çalışmaya alınan 108 hastanın 61 (\%56.5) tanesi erkek, yaş ortalaması 54.5 15.1 (19-89) idi. Etiyolojik nedenler; kronik hepatit B 33 hasta (\%30), kronik hepatit C 19 (\% 17), kronik hepatit B + kronik hepatit C 2 (\%2), delta hepatiti 12 (\%11), Wilson hastalığı 6 (\%6), kardiyojenik 2 (\%2), otoimmün hepatit, hemokromatosiz, kalitsal metabolik hastalık, alkol, portal ven trombozu, konjenital hepatik fibrosiz birer hasta iken, kriptojenik siroz 27 hasta (\%25) idi. Kriptojenik siroz hastalarının 14 tanesi erkek (\%51.9), yaş

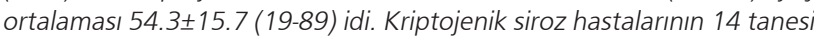
(\%52) Adult Treatment Panel 3 kriterlerine göre metabolik sendrom olarak değerlendirildi. Sonuç: Siroz etiyolojisinde en sık neden viral hepatitlerdir. Hastaların dörtte biri kriptojenik sirozdur ve bu hastaların yarısı metabolik sendrom kriterleri taşımaktadır, bu hastalar non-alkolik steatohepatit zemininde gelişen siroz olarak tanımlanabilir. Tüm siroz nedenlerinin onda birinden non-alkolik steatohepatit sorumludur.
\end{abstract}

Anahtar kelimeler: Siroz, steatohepatit, kriptojenik siroz
Background and Aims: In our region and Turkey, the most common cause of liver cirrhosis is chronic viral hepatitis. Cryptogenic cirrhosis is described if no causative factors can be found. Nonalcoholic fatty liver disease is a disease that precedes chronic inflammation and can result in liver cirrhosis, which is not considered the secondary cause of liver steatosis. In this study, we aimed to discuss the etiology of cirrhosis and assess its role in nonalcoholic fatty liver disease. Materials and Method: We conducted a clinical study on patients between January 2013 and December 2014 and/or a biopsy diagnosis of patients diagnosed with cirrhosis. Detailed history of the patients was collected and physical examination was performed. Body mass index was calculated. Routine examinations were done, and detailed laboratory and radiological analyses were performed. When the etiological cause could not be found, the patients were diagnosed as having cryptogenic cirrhosis. Based on Adult Treatment Panel III, these patients were evaluated according to the criteria for metabolic syndrome. They met the criteria for nonalcoholic steatohepatitis cirrhosis. Results: 108 patients were enrolled in the study: 61 (56.5\%) were males, with a mean age of $54.5 \pm 15.1$ (19-89) years. Thirty-three patients had chronic hepatitis $B$ (30\%), 19 had chronic hepatitis C (17\%), 2 had chronic hepatitis B and chronic hepatitis $C(2 \%), 12$ had hepatitis $D(11 \%), 6$ had Wilson's disease (6\%), and 2 had cardiogenic shock (2\%). Other eitologic factors included autoimmune hepatitis, hemokromatosiz, hereditary metabolic disorders, alcohol, portal vein thrombosis, and congenital hepatic fibrosis. Twenty-seven patients had cryptogenic cirrhosis (25\%). Of the 27 patients, 14 were males (51.9\%), with a mean age of $54.3 \pm 15.7$ (19-89) years. Based on Adult Treatment Panel III, those cryptogenic cirrhosis patients $(14,51.9 \%)$ were evaluated according to the criteria for metabolic syndrome. Conclusion: Viral hepatitis is the most common cause of cirrhosis in our region. One quarter of the patients were diagnosed with cryptogenic cirrhosis, and half of them met the metabolic syndrome criteria. These patients can be defined as experiencing cirrhosis due to nonalcoholic fatty liver disease. One of the major ten causes of cirrhosis is nonalcoholic steatohepatitis.

Keywords: Cirrhosis, steatohepatitis, cryptogenic cirrhosis

Batı ülkelerinde en sık siroz nedeni hepatit C virüsü (HCV) ve alkol iken, Asya-Pasifik ve Afrika ülkeleri için hepatit B virüsü (HVB) en sık etiyolojik nedendir. Türkiye'de sirozun \%60'la en sık nedeni 2007 'de viral hepatitler olarak bildirilmiştir. Sosyo-ekononomik gelişmeler ve hepatit aşısı son zamanlarda epidemiyolojik ve etiyolojik nedenleri dramatik olarak değiştirmiştir (2-5). Non-alkolik karaci-

Uyanıkoğlu A. The role of steatohepatitis in cirrhosis etiology. The Turkish Journal of Academic Gastroenterology 2020;19:17-20. DOI: 10.17941/ agd.723285

Geliş Tarihi: 03.02.2019 • Kabul Tarihi: 15.04.2020 
ğer yağlanması (NAYKH=non-alcoholic fatty liver disease-NAFLD) erişkin ve çocukların dünyada en fazla görülen kronik karaciğer hastalığı formudur. Obezite insidansının artışıla paralel olarak, tüm dünyada, tüm yaş gruplarında dramatik olarak artmaktadır. NAFLD, basit yağlanmadan, karaciğer sirozu ve hepatosellüler karsinoma (hepatocellular carcinoma-HCC)'ya ilerleyebilen non-alkolik steatohepatite (NASH) kadar farklı derecedeki durumlar için kullanılan genel bir isimdir (6-8).

ABD'de NAFLD'ın retrospektif olarak popülasyonun yaklaşık \%30'unu, NASH'in \%5'ini etkilediği düşünülmektedir. NASH'li hastaların yaklaşık yarııı kardiyovasküler ve malignite nedeniyle vefat etmektedir. NASH'li hastalarda 3. en sık ölüm nedeni sirozdur, NASH ABD'de en sık karaciğer transplantasyon nedenidir. 50 yaş üzeri diyabetes mellituslu (DM) veya obez hastaların $\% 66$ 'sında ileri fibrozlu NASH olduğu düşünülmektedir $(8,9)$.

Dünyada NAFLD insidansı \%9-34 arasında olup, bu hastaların \%10-20'si NASH'e, \%8.3'ü siroza ilerlemektedir (10).

Karaciğer sirozunun etiyolojisinde Türkiye'de ve bölgemizde en önemli sebep kronik viral hepatitlerdir (11-14). Etiyolojik bir neden bulunamazsa kriptojenik siroz olarak tanımlanır. Bu çalışmada bölgemizde siroz etiyolojisi ve siroz etiyolojisinde NASH'in yerini değerlendirmeyi amaçladık.

\section{GEREÇ ve YÖNTEM}

Çalışmaya Ocak 2013- Aralık 2014 arasında klinik ve/veya biyopsi ile siroz teşhisi konulmuş hastalar alındı. Hastaların ayrıntılı anamnezi alındı, fizik muayeneleri yapıldı, vücut kitle indeksleri (VKi) hesaplandı. Rutin tetkikleri, etiyolojik açıdan ayrıntılı laboratuvar ve radyolojik incelemeleri yapıldı. Etiyolojik bir neden bulunamayan hastalar kriptojenik siroz kabul edildi, bu hastalar Adult Treatment Panel 3 (ATP 3) kriterlerine göre metabolik sendrom açIsından değerlendirildi (11), bu kriterlere uyan hastalar NASH zemininde gelişen siroz kabul edildi.

\section{BULGULAR}

Çalışmaya alınan 108 hastanın 61 (\%56.5) tanesi erkek,

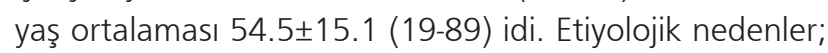
kronik hepatit B 33 hasta (\%30), kronik hepatit C 19 (\%17), HBV+HCV 2 (\%2), delta hepatiti 12 (\%11), Wilson hastalı̆ıı 6 (\%6), kardiyojenik 2 (\%2), otoimmün hepatit, hemokromatosiz, kalitsal metabolik hastalık, alkol, portal ven trombozu, konjenital hepatik fibrosiz birer hasta iken kriptojenik siroz 27 hasta (\%25) idi (Tablo 1).

Kriptojenik siroz hastalarının 14 tanesi erkek (\%52), yaş ortalaması 54.3 \pm 15.7 (19-89) idi. Kriptojenik siroz hastaIarının 14 tanesi (\%52) ATP III kriterlerine göre metabolik sendrom olarak değerlendirildi.

\section{TARTIŞMA}

Karaciğer sirozunun etiyolojisinde Türkiye'de ve bölgemizde en önemli sebep kronik viral hepatitlerdir $(5,12$ 14). Orta Anadolu'da yapılan bir çalışmada toplam 135

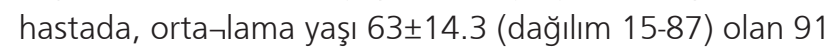
erkek hasta (\%67.4) ve 44 kadın hastada sirozun başlıca etiyolojik nedenleri HBV (n: 52, \%38.5) ve kriptojenik (n: 33, \%24.4) idi. Sirozun en sık nedeni erkeklerde HBV (\%49.5) ve kadınlarda kriptojenik karaciğer sirozuydu

Tablo 1. Siroz saptanan 108 hastanın etiyolojkk dağılımı, etiyolojide NASH'ın yeri.

\begin{tabular}{|lcc|}
\hline Hastalık & Sayı & Yüzde \\
\hline Kriptojenik & 27 & $\% 25$ \\
\multicolumn{1}{c}{ NASH } & 14 & $\% 52$ \\
NASH olmayan & 13 & $\% 48$ \\
\hline Hepatit B & 33 & $\% 30$ \\
\hline Hepatit C & 19 & $\% 17$ \\
\hline Delta hepatiti & 12 & $\% 11$ \\
\hline Wilson & 6 & $\% 5$ \\
\hline Hepatit B + Hepatit C & 2 & $\% 2$ \\
\hline Kardiyojenik & 2 & $\% 2$ \\
\hline Diğerleri (hemokromatoz, otoimmün, alkol vb) & 7 & $\% 7$ \\
\hline
\end{tabular}

NASH: Non-alkolik steatohepatit 
(\%40.9) (13). Bizim çalışmamızda da en sık etiyolojik neden bu çalışmaya benzer olarak hepatit B idi. Yaş grubu bu seride bizim serimize göre yaklaşık bir dekat daha yaşlı idi, bu seri kadar olmasa da erkek hasta sayısı bizim serimizde de daha fazla idi. Kriptojenik sirotik hastalarımız her iki cinsiyette benzer oranda olup, bu serideki gibi kadın dominansı yoktu.

NAFLD ve metabolik sendrom ilişkisi iyi dökümante edilmiştir. Obezite, tip 2 DM ve dislipidemi NAFLD ile beraber en sık metabolik risk faktörleridir. Metabolik sendrom kompanentlerinden obezite ve diyabet ile HCC riski arasında güçlü kanıtlar gösterilmiştir. Epidemiyolojik veriler obezite, diyabet, NAFLD ve HCC riskinde paralel artışı göstermiştir (15). NAFLD sıklıkla metabolik sendromun özelliklerini gösterir ve insülin rezistansı ile ilişkilidir. Tanıda altın standart yöntem halen karaciğer biyopsisidir. Radyolojik yöntemler steatoz varlığını belirlemede yeterli olsa da NASH ve fibrozis varlığını göstermede yetersiz kalmaktadırlar (16). Biz çalışmamızda sirotik hastaları değerlendirdiğimizden biyopsi yapmadık. Klinik, laboratuvar ve görüntüleme yöntemlerine göre siroz tanısı koyduk. Kriptojenik sirozlu hastalardan ATP III kriterlerine göre NASH değerlendirildi (11). Kriptojenik sirozlu hastalarımızda HCC saptanmadı.

2000-2007 yılları arasında Haseki Eğitim ve Araştırma Hastanesi'nde karaciğer sirozu tanısı ile takip edilmiş 268 'i erkek (\%57.3) ve 200'ü kadın (\%42.7), yaşları 1690 arasında değişen toplam 468 hastanın retrospektif olarak incelendiği bir tez çalışmasında kriptojenik gruptaki toplam 132 olgunun (\%28) 59 tanesinde (\%45), HBV siroz grubundaki toplam 195 olgunun (\%41) 36 tanesinde (\%18), HCV sirozlu toplam 75 olgunun (\%16) 19 tanesinde (\%25), primer biliyer siroz (PBS) grubundaki toplam 21 olgunun (\%4) 2 tanesinde (\%10), diğer gruptaki 45 olgunun 5 tanesinde (\%11) tip 2 DM saptanmıştır. Kriptojenik siroz grubunun tip 2 DM pozitifliği diğer tüm etiyolojisi bilinen gruplara göre anlamlı derecede yüksek oranda tespit edilmiştir $(p<0.01)$. Kriptojenik grupta tip 2 DM sıklığı HBV sirozlu, HCV sirozlu, PBS'lu ve diğer gruptan anlamlı derecede yüksek saptanmıştır $(p<0.001)$ (14). Türkiye'nin Batısında da bizim serimizde olduğu gibi

\section{KAYNAKLAR}

1. Cabibbo G, Palmeri L, Palmeri S, Craxì A. Should cirrhosis change our attitude towards treating non-hepatic cancer? Liver Int 2012;32:21-7

2. Grant BF, Dawson DA, Stinson FS, et al. The 12-month prevalence and trends in DSM-IV alcohol abuse and deᄀpendence: United States, 1991-1992 and 2001-2002. Drug Alcohol Depend 2004;74:223-34. en sık siroz nedeni olarak HBV saptanmıştır. Serimizle benzer oranda kriptojenik siroz hastaların yaklaşık dörtte birini teşkil etmektedir. Yine bizim bulgularımızı destekler nitelikte kriptojenik sirozlu hastalarda DM, diğer etiyolojik nedenli sirotik hastalara göre anlamlı olarak daha yüksek oranda saptanmıştır. Bu seride kriptojenik sirotik hastalar NASH açısından irdelenmemiş olup, muhtemelen kriptojenik sirozlu diyabetik hastalarda etiyolojik neden NASH idi. Sirotik ve kronik hepatitli hastalarda DM sıklığını araştıran benzer başka bir çalışmada da benzer şekilde kriptojenik (\%67.7), HCV (\%56.8) ve alkole bağlı karaciğer hastalarında (\%60), HBV'li (\%38.9) olgulara göre daha yüksek oranda bozulmuş açlık glikozu ve DM saptanmış$\operatorname{tir}(p=0.017),(17)$.

Tedavide ilk akla gelmesi gereken yaşam tarzı değişiklikleridir. Fizik aktivitenin arttırıması, ılımlı ölçüde kilo kaybı, kalori alımının azaltılması temel yaklaşımlardır. Medikal tedavide bazı ilaçların erken dönemde etkinlikleri gösterilmiş olmakla birlikte geç dönem sonuçları halen bilinmemektedir. Medikal tedavinin yeterli olmadığı, özellikle morbid obez hasta grubunda bariatrik cerrahi yaklaşımlar düşünülebilir. Ancak günümüzde NASH tedavisinde evrensel olarak kabul edilen bir tedavi modalitesi halen bulunmamaktadır (16). ABD'de 75-100 milyon kişide NAFLD olduğu düşünülmekte, bu hastalarda erken dönemde NASH'in belirlenmesi ve tedavisiyle dekompanse siroz ve transplanta gidişin önlenmesine yardımcı olunabilinir (18). Çalışmamızda sirozun en önemli nedenlerinden birinin NASH olduğunu (kriptojenik sirozlu hastaların yaklaşık yarısı) gösterdik. NAFLD ve NASH farkındalığının artması, bu hastaların ileri safhalara gelmeden erken tespit edilerek, doğru tedavi edilmesinin ülkemiz ve bölgemiz için önemli olduğunu düşünüyoruz.

Sonuç olarak; siroz etiyolojisinde en sık neden halen viral hepatitlerdir. Hastaların dörtte biri kriptojenik sirozdur ve bu hastaların yarısı metabolik sendrom kriterleri taşımaktadır, bu hastalar NASH zemininde gelişen siroz olarak tanımlanabilir. Tüm siroz nedenlerinin onda birinden NASH sorumludur diyebiliriz.

\section{“Tüm yazarlar herhangi bir çıkar çatışması olmadığını kabul ederler."}

3. Di Bisceglie AM. Natural history of hepatitis C: its impact on clinical management. Hepatology 2000;31:1014-8.

4. Merican I, Guan R, Amarapuka D, et al. Chronic hepatitis B virus infection in Asian countries. J Gastroenterol Hepatol 2000;15:1356-61.

5. Ökten A. Karaciğer sirozu. In: Büyüköztürk K, Atamer T, Dilmener M, eds. İç Hastalıkları Cilt-1, 1st edn. Ankara: No-bel Tıp Kitabevi, 2007:1077-88 
6. Voiculescu M, Nanau RM, Neuman MG. Non-invasive biomarkers in non-alcoholic steatohepatitis-induced hepatocellular carcinoma. J Gastrointestin Liver Dis 2014;23:425-9.

7. Ferolla SM, Armiliato GNA, Couto CA, Ferrari TCA. The role of intestinal bacteria overgrowth in obesity-related nonalcoholic fatty liverdisease. Nutrients 2014;6:5583-99.

8. Paolella G, Mandato C, Pierri L, et al. Gut-liver axis and probiotics: their role in non-alcoholic fatty liver disease. World J Gastroenterol 2014;20:15518-31.

9. Patel YA, Berg CL, Moylan CA. Nonalcoholic fatty liver disease: key considerations before and after liver transplantation. Dig Dis Sci 2016;61:1406-16.

10. Kew MC. Obesity as a cause of hepatocellular carcinoma. Ann Hepatol 2015;14:299-303.

11. Galper BZ, Wang YC, Einstein AJ. Strategies for primary prevention of coronary heart disease based on risk stratification by the ACC/AHA Lipid Guidelines, ATP III Guidelines, Coronary Calcium Scoring, and C-Reactive Protein, and a Global Treat-All Strategy: A Comparative--Effectiveness Modeling Study. PLoS One 2015;10: e0138092.
12. Seçkin $Y$, Gülşen MT, Kantarçeken B, Dülger AC, Uyanıkoğlu A. Doğu ve Güneydoğu Anadolu Bölgesindeki sirozlu olguların değerlendirilmesi. 11. Hepato-Gastroenteroloji Kongresi, Bildiri Kitabı. 2530 Eylül 2014, Kıbrıs, P-213, 103.

13. Başyiğit S, Asiltürk Z, Sapmaz F, et al. Hepatitis B virus is still the most common etiologic factor of liver cirrhosis: Results from a single center in Turkey. Dicle Med J 2015;42:416-21.

14. Erkal T. Non alkolik yağlı Karaciğer hastalığının (Nonalcoholic Fatty Liver Disease, NAFLD) siroz panelindeki Yeri. Uzmanlık Tezi, Haseki Eğitim ve Araştırma Hastanesi, İstanbul, 2008.

15. Streba LA, Vere CC, Rogoveanu I, Streba CT. Nonalcoholic fatty liver disease, metabolic risk factors, and hepatocellular carcinoma: an open question. World J Gastroenterol 2015;21:4103-10.

16. Çolak Y, Tuncer I. Nonalcoholic fatty liver disease and steatohepatitis. J Ist Faculty Med 2010;73:85-91.

17. Yılmaz Ö, Kasap E, Yüceyar H. Four-year evaluation and association between chronic liver disease and diabetes mellitus in a patient. Akademik Gastroenteroloji Dergisi 2012;11:18-23.

18. Rinella ME. Nonalcoholic fatty liver disease: a systematic review. JAMA 2015;313:2263-73. 